\title{
TLS MODELS GENERATION ASSISTED BY UAV SURVEY
}

\author{
F. Chiabrando ${ }^{a}$, V. Di Pietra ${ }^{\text {b }}$, A. Lingua ${ }^{\text {b }}$, P. Maschio, F. Noardo ${ }^{\text {b }}$, G. Sammartano ${ }^{\text {a }}$,A. Spanò a* \\ a Politecnico di Torino, of Architecture and Design, Viale Mattioli 39, 10125, Torino, Italy. \\ b Politecnico di Torino, Department of Environment, Land and InfrastructureEngineering, c. Duca degli Abruzzi 24, 10129, Torino, \\ Italy. \\ (filiberto.chiabrando,andrea.lingua,giulia.sammartano,antonia.spano)@ polito.it
}

Commission V, WG V/2

KEY WORDS: TLS, UAV photogrammetry, 3D modelling, techniques fusion, data fusion, Alpine Heritage

\begin{abstract}
:
(TLS, Terrestrial Laser Scanning), and large scale mapping derived by UAV (Unmanned Aerial Vehicle) survey. This paper refers an example of 3D survey and reality based modelling applied on landscape and architectural assets. The choice of methods for documentation, in terms of survey techniques, depends primarily on issues and features of the area.

The achieved experience, allow to consider that the easy handling of TLS has enabled the use in limited spaces among buildings and collapsed roofs, but the topographic measure of GCPs (Ground Control Points), neither by total station nor by GPS/RTK technique, was easily feasible. Even more than proving the ability of the integration of TLS and UAV photogrammetry to achieve a multisource and multi-scale whole model of a village, the experience has been a test to experiment the registration of terrestrial clouds with the support of control points derived by UAV survey and finally, a comparison among different strategies of clouds registration is reported. Analysing for each approach a number of parameters (number of clouds registration, number of needed points, processing time, overall accuracy) the further comparisons have been achieved.

The test revealed that it is possible to decrease the large number of terrestrial control points when their determination by topographical measures is difficult, and it is possible to combine the techniques not only for the integration of the final 3Dmodel, but also to solve and make the initial stage of the drafting process more effective.
\end{abstract}

\section{INTRODUCTION}

We are currently witnessing the interest toward 3D documentation techniques for Cultural Heritage for landscape conservation and valorisation processes. The need of complete and multi-scale models is becoming increasingly widespread and legitimize the use of integrated sensors for multiples views and multi-resolution models.

The new researches in these disciplines are applied at different scales and the terrestrial acquisitions by TLS together with aerial documentation by the use of Unmanned Aerial Vehicles (UAV) offers almost new potentialities in the large-scale, competitive as well as terrestrial one (Grenzdörffer et al., 2008). Focusing these researches is interesting in context of complex documentation, applied at specific valuable landscape of the built and natural heritage, that are located often in arduous areas since they are very scarcely accessible. The previous issues lead us to choose specific survey tools able to reach high level of detail and at the same time, a relatively large area of coverage. In this domain, it requires more and more attention for sustainability issues and collective participation dynamics, as in the context of application of this paper that is aimed at the documentation of an alpine abandoned village

Nowadays alpine villages are highly observed and focused by European and local funding projects with the aim to recover them and to create conditions people can live there again. In the Alpine context, a group of villages in the Castelmagno area has been subject to a series of multidisciplinary activities focused on protection and promotion of Alpine culture and local economy in line with the Regional Landscape Plan guidelines, and supporting decision-making processes about enhancement scenarios (Coscia et al.,2015).

Especially when small rural villages or mountain communities are involved in enhancement projects, the documentation technologies based of advanced Geomatics tools offer a significant support in these proposals, in term of quickness, precision, cost-cutting, and in short, sustainability (BotequilhaLeitão \& Ahern, 2002).

It should however be considered that in spite of the versatility of the methods, their application through a standard workflow cannot be so effective in the context of situations which are not at all ordinary.

From this consideration, it follows the entire process carried out to compare different recordings of terrestrial laser scans through various solutions offered by the alignment systems of the clouds and through the data holdings from the aerial survey by drones. One of the main important follow objective was the combination of terrestrial scanning and low aerial acquisition with the aim to achieve multi-scale models.

\section{DATA AND TECHNIQUES FUSION: AERIAL AND TERRESTRIAL APPROACHES}

The issues of merging data and methods using different sensors with the aim to generate (Kersten, \& Lindstaedt, 2012a,2012b; Hullo et al.,2012; Roncella et al. 2012; Remondino et al., 2014; Martin-Beaumont et al., 2013) models and useful 2D/3D representations for land documentation processes are surely very timely. 
In the last decade, one of the more pursued aim of integrating methods for $\mathrm{CH}$ data recording was the generation of multiscale 3D models from TLS and digital photogrammetry (Bastonero et al., 2014; Blais \& Beraldin 2006; Nony et al., 2012; Patias et al., 2012; Koutsoudis, et al., 2013; Philips et al.,2009 ). The more estimated contribution of terrestrial laser scanning technique was the production of dense 3D point-clouds, useful to create high-resolution geometric models, while digital photogrammetry has been considered more suited to produce high-resolution textured 3D models.

This approach has been tested a variety of times also because of the extreme diversity of cultural heritage, ranging from the places of landscape and archaeological interest, to the architectural heritage and to the mobile heritage, different for dimensional features, artistic value, health or state of conservation. (Moussa et al., 2012; Vosselaman, 2002; Ramos \& Remondino, 2015; Maiellaro et al., 2015; Xu et al., 2014; Guidi et al., 2009; Wenzel et al., 2012).

Currently, the increasingly widespread UAV photogrammetry has been largely tested in applications aimed to cultural heritage (Irschara et al., 2010; Gruen, 2009; Suerbier \& Eisenbeiss, 2010; Nex \& Remondino, 2013). The most widespread purpose concerning the terrestrial and aerial imagery is intended to supplement the final models, being able to reach high degrees of completeness, since data are combined from terrestrial and aerial point of view.

As a cornerstone of the test that will be described in this paper, there are two important considerations, one concerning the terrestrial laser technology, while the second is focused on the automatic processes of SFM pertaining the use of digital photogrammety. The technology and softwares for the recording of terrestrial clouds are more and more specialized in order to offer different ways of scan alignment, adapting themselves to the complexity of the requirements forthe objects of interest. They are the use of targets of different types, the use of natural points with unknown spatial coordinates, the clouds union via pattern recognition, the ability to group the clouds in different sets, assigning the spatial reference in deferred stages.

On the other hand, the high performance of SFM systems able to search highest sets of tie-point and to generate very complex point-clouds, makes this method more and more independent from topographic systems of determination of control points calculated due to topographical.

Despite of these high easily adoptable specializations and opportunities offered to enlarge the users, the need to work sometimes in critical areas induced to investigate the possibilities of optimization offered by the integration of the methods in the initial stages of the application, which allows to reach to better results than those obtained by separate applications

\section{THE FUSION TECHNIQUES IN THE ALPINE LANDSCAPE OF CASTELMAGNO}

\subsection{The test case and aim of survey}

The test area is an abandoned village named Campofei in a valley of Cuneo district, Piedmont Region (Italy). Figure 1 First of all the UAV survey was employed for documenting the relations between the alpine villages and the surrounding landscape, enabling also the reference of very large scale data to the current and dated regional digital cartography. However, the TLS survey has been purposed to document the urban planning aspects and those related with architectural elements and constructive systems. The fact that buildings aggregates present an high level of internal cohesion, mostly climbing steep slopes, make the acquisition phase rather difficult since it request an high resolution and high level of detail in order to base proper projects of requalification, even when they present as a state of ruins.

All this explains the reason why it was necessary a set of different scale information, which have determined the first start of the project to schedule both types of survey, aerial and terrestrial ones.

The high difficulty presented by the terrestrial laser scanning application, led to envisage the study of a fusion of methods. In particular, the use of control points extracted from UAV DSM point cloud or 3D model to better control the recording of terrestrial clouds, since the UAV flight was the single type of survey that could dominate from above the intricate combination of environments in a state of ruin.

The following set of images document the steepness of the slopes valleys, the forest that surrounds the villages, the houses in ruins and the natural vegetation that has invaded the home space. We can observe that the case study presents a series of complexity similar to those that distinguish the archaeological heritage, for the state of ruin of built heritage, to which is added the difficult access to more levels, to reach the village and plan the UAV flight, to reach the individual homes and realize the laser scanning survey.
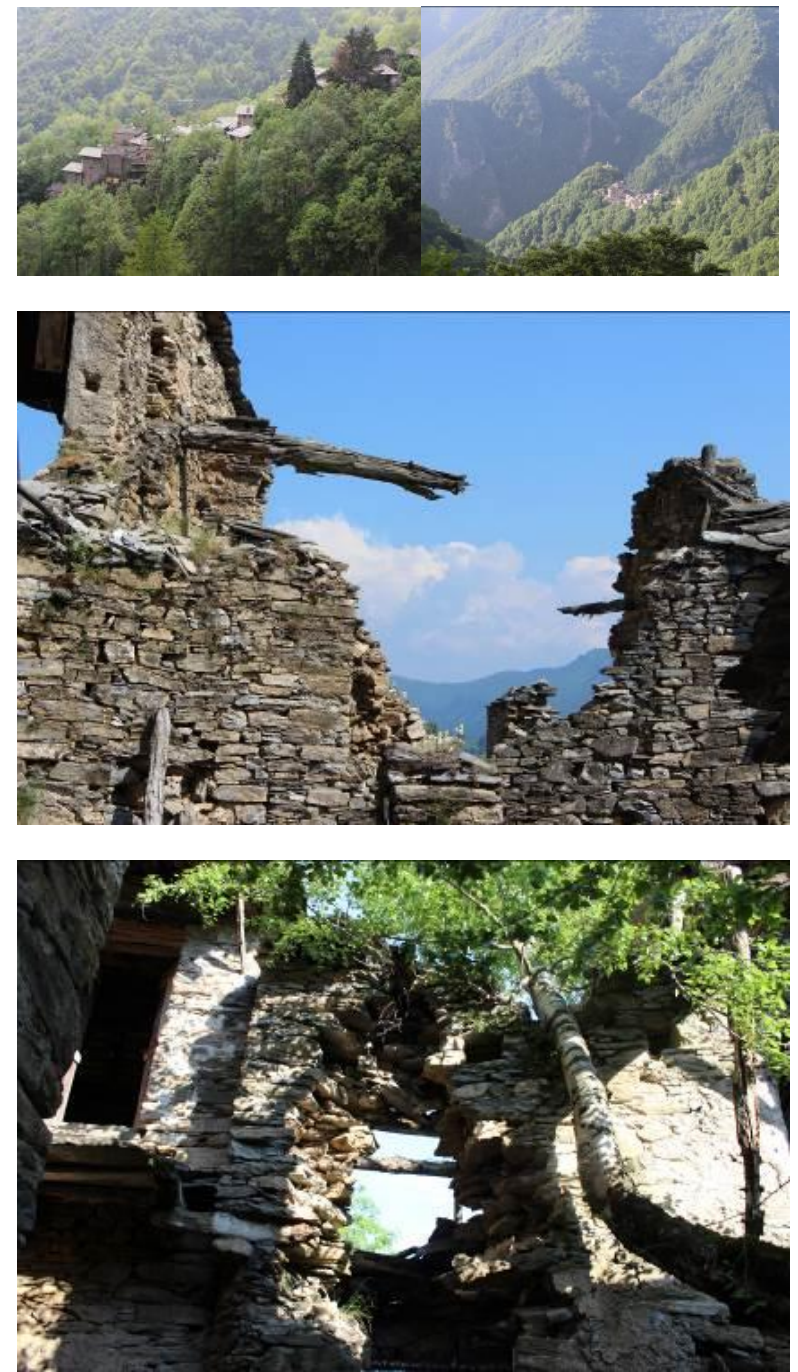

Figure 1 (a,b,c,d,) The steepness of the slopes valleys, the forest that surrounds the villages, the houses in ruins and the natural vegetation that has invaded the home space. 


\subsection{TLS survey}

The laser survey has been achieved by the Focus ${ }^{3 \mathrm{D}} \mathrm{Cam} 2$, from Faro instruments (http://www.faro.com/products/3dsurveying/laser-scanner-faro-focus-3d).

The scanner is the well known phase shift instrument manageable and user friendly that allow to acquire in short time million of points at a distance in the used configuration, up to $130 \mathrm{~m}$. According to characteristic of the area (narrow and non linear paths with a lot of occlusion) several scans were acquired in order to correctly document all the main parts of the village. In the following Figure 2 the main characteristics of the acquired data are reported, and in Figure 3the spatial location of scan positions is represented.

The acquisition parameters reveal that the laser survey has been organized according to the usual conditions for obtaining detailed 3D models at the architectural scale: acquisition distances that involves an average distance between the points of the cloud of 3-4 mm, clouds of about $20 \mathrm{ml}$ size of etc.

\begin{tabular}{|c|c|c|c|c|c|c|}
\hline \multicolumn{7}{|c|}{ SCANS ACQUIIITION } \\
\hline & $\begin{array}{l}\text { Tot } \\
\text { acquistion }\end{array}$ & \begin{tabular}{|l}
$n^{\circ}$ registered \\
accaustition
\end{tabular} & $\begin{array}{l}\text { meann } \\
\text { poinst/sens }\end{array}$ & Resolution (MPt) & $\begin{array}{c}\text { Quality (times } \\
\text { of meas for } \\
\text { each point pot }\end{array}$ & $\begin{array}{c}\text { Scanning } \\
\text { area }\end{array}$ \\
\hline Scanner FARO Focus3D & 30 & 28 & $20^{*} 10^{6}$ & $\begin{array}{r}1 / 4 \\
(1 \mathrm{pt} / 6 \mathrm{~mm} \\
\text { at } 10 \mathrm{~m})\end{array}$ & $4 \mathrm{x}$ & $360^{\circ}$ \\
\hline
\end{tabular}

Figure 2. Acquisition parameters of TLS survey

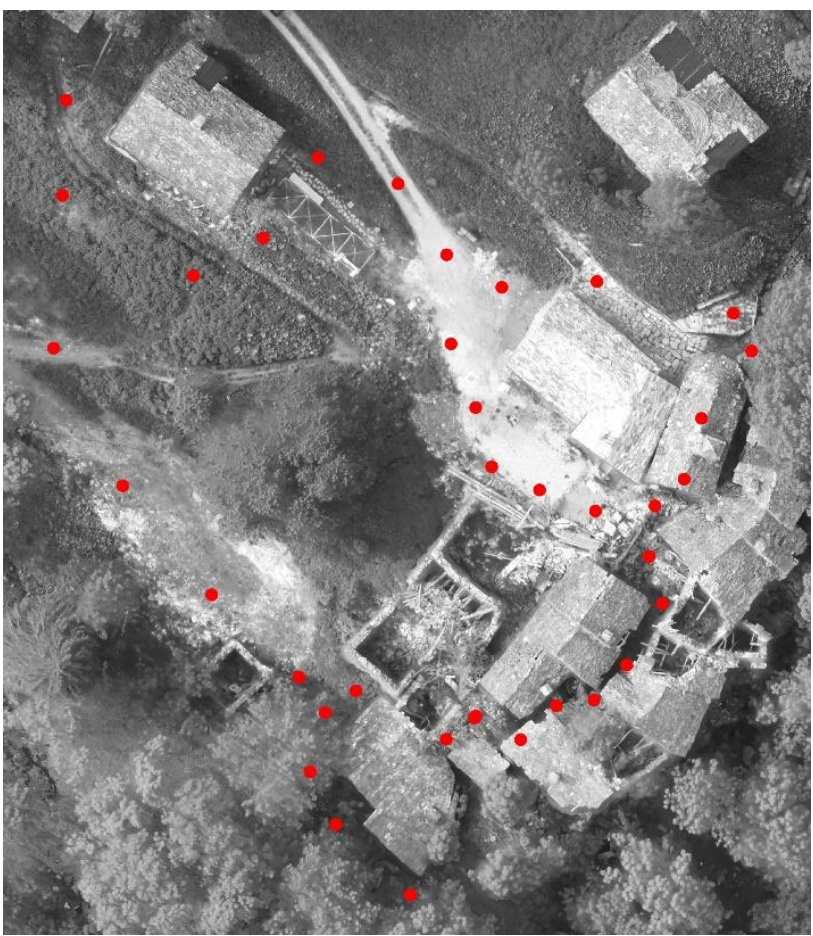

Figure 3. Location of scan positions inside and outside the village.

Although the planning of TLS survey had expected the distribution and the measure by total station of a number of well distributed targets (Figure 4), the recording of the clouds was very difficult, especially in the central area of the pool of homes, particularly unattainable by the usual topographic measurements.

3.2.1. First scans registration. The alignment of point cloudsperformed using Scene software has been possible using multiple solutions. The cloud to cloud function (Bae \& Lichti,
2006; Gressin et a., 2013), that exploit the shape recognition of surfaces, detected by the individual scans. Despite the high overlap between adjacent scans, Figure 3 illustrate how the recording was possible only grouping in two different scans set (block 1.2, Figure 6) and only the entire block of scans has been successfully registered via targets after a shape recognition registration into the two blocked groups. The accuracy results reported in Figure 5 are rather worse than similar architectural scale applications, but a little lower value than two centimetres on the target that means a few centimetres for all the other points is not far from the order of magnitude searched.

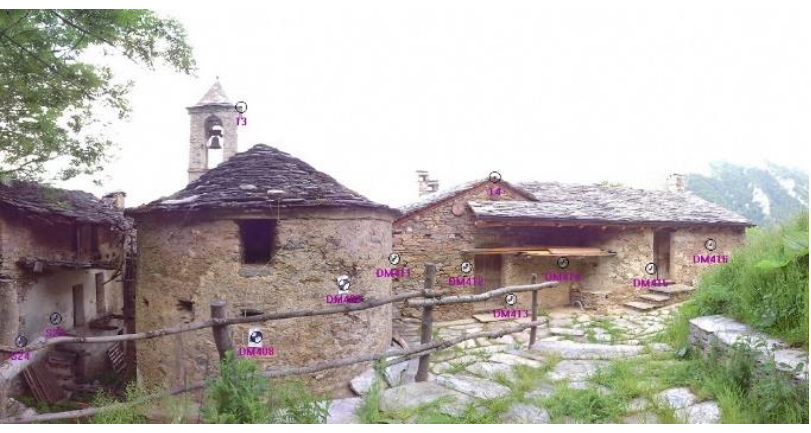

Figure 4. The use of measured targets for the registration phase.

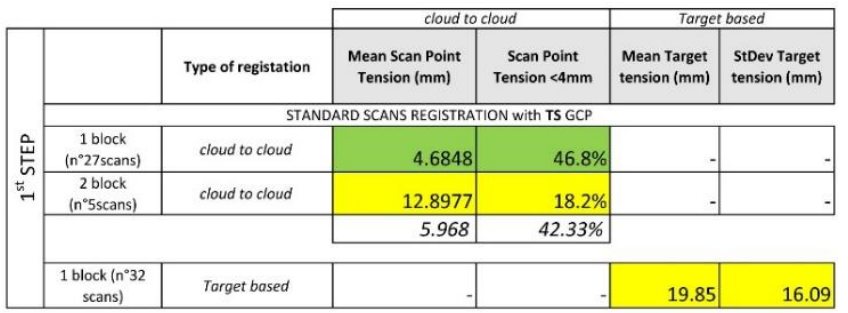

Figure 5. Accuracy results after clouds registration: $1^{\circ} \mathrm{STEP}$

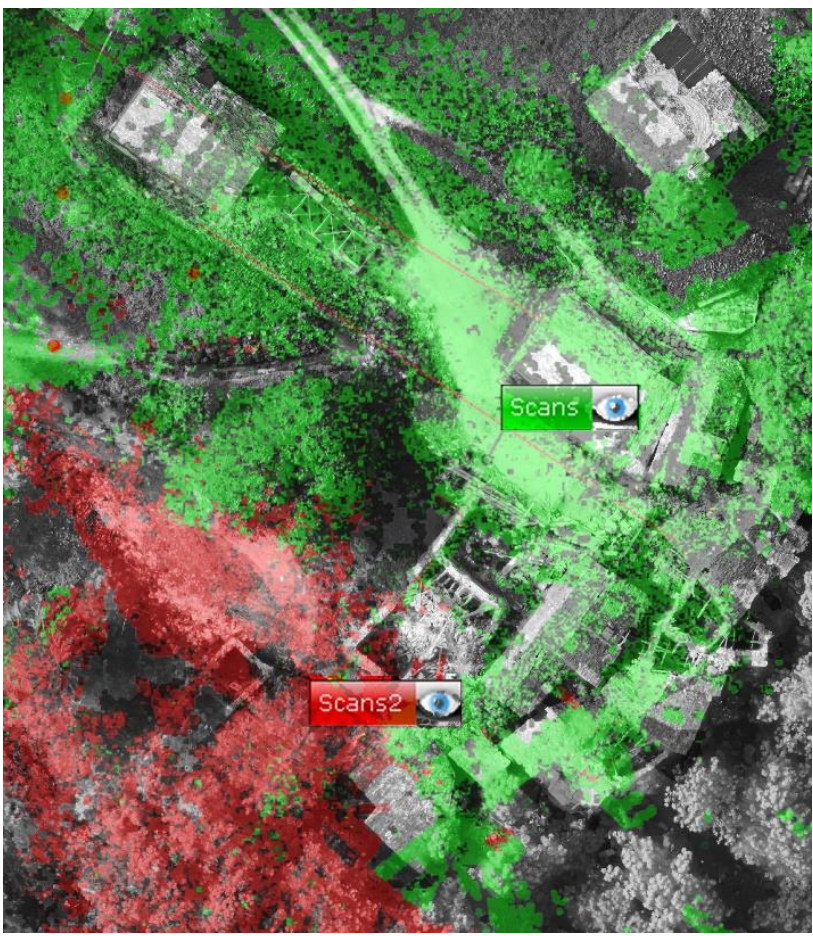

Figure 6. The two groups of scans covering the upper and the lower side of the village. 


\subsection{UAV acquisition by hexacopter}

The high scale mapping of the hamlets in the Castemagno area has been achieved by the multirotor platform produced by Hexacopter Microcopter (Errore. L'origine riferimento non è stata trovata.7). The aircraft is equipped with six rotating wings, weighs approximately $1.2 \mathrm{~kg}$ including batteries, and with a maximum load (payload) of $1 \mathrm{~kg}$. In the employed version the system is equipped in the lower part by a commercial off the shelf (COTS) digital camera, namely a Sony Nex 5 that uses an infrared control system managed by the remote controller for image acquisition (Chiabrando et. al 2013). From the operation point of view the maximum flight time is about $12-15 \mathrm{~min}$, nominal speed $3-5 \mathrm{~m} / \mathrm{sec}$ with a GSD at $100 \mathrm{~m}$ of about $3.2 \mathrm{~cm}$ using the Sony Nex 5 digital camera.

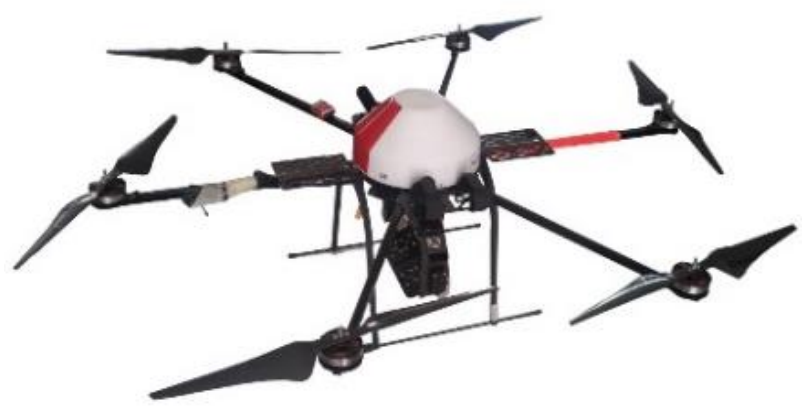

Figure 7 The multi-rotor UAV that has performed the flight

Using the Hexacopter, the flight plan is managed by the Mikrokopter tool OSD that connects the platform to ground station. The tool is exploited to set all the parameters of the flight plan, using as reference map of the area, corresponding to one of the imagery made available by several on-line map server. The flight planning approach is ordinary, based on the definition of waypoints; as usual the aim of the flight is to follow the direction between the starting and ending points according to the defined azimuth. The employed tool in the used version 2.00 does not allow the flight planning according to the slope of the terrain (Taccola et a., 2013;Ballarin et al., 2013). This was a crucial problem in the area of Campofei since the orography of the area was quite "rough" with large gap and this situation suggest to divide one simple flight in two in order to maintain the same scale between the different parts.

The height of the different flights was set up at $70 \mathrm{~m}$ in order to obtain a Ground Sample Distance of $0.022 \mathrm{~m}$ with large overlapping in both the directions: $80 \%$ of longitudinal overlapping and $70 \%$ lateral. As a results 7 stripes in the lower part and 7 in the high part with a cross stripe as well were performed in the area of Campofei.

Since the acquisition of the images was realized for extracting metric information through a photogrammetric process, several markers have been positioned on the terrain. The points have been used in the Bundle Block Adjustment (Triggs et al., 200) as Ground Control Points (GCPs) and for checking the accuracy of the final results as Check Points (CPs).The surveying operations were carried out using a Real Time Kinematic approach in order to obtain a centimetric accuracy on the surveyed points. As reference a vertex of the micro-geodetic network realized for set up a reference system on the area was employed since in that alpine area the GSM connection did not work.
3.3.1 Data processing. Subsequently for data processing the well known software Pix4D was employed. As other main commercial software aimed to photogrammetric purposes, the Pix4D workflow is based on a Structure From Motion approach (Robertson \& Cipolla, 2009; Ahmadabadian et al.,2013 Roncella et al.,2011; Del Pizzo et al , 2011;Fritsh et al ., 2011; Fritsh et al ., 2012) of four steps: initial processing, point cloud densification, 3d model realization, DSM and orthomosaic generation.

After the initial processing, especially for mapping generation, the GCPs and CPs are inserted in order to check the accuracy of the generated products. In the analyzed area (about $0.18 \mathrm{Km}^{2}$ ) 626 images were processed and oriented using 20 GCPs and 10 CPs, the results of the Bundle Block adjustments ( were good but not excellent due probably again to the problem connected to the particular orography of the terrain. On the used points as mean RMS on the GCPs we obtain $0.041 \mathrm{~m}$ and on the CPs $0.062 \mathrm{~m}$, this results were considered sufficient for the test reported in the present paper. During the process 4.990.225Tiepoints were extracted (Figure 8 report a screen shot of the oriented images and the extracted TPs), the dense cloud process with half image size $1 / 2$ option, extract 187.218 .110 of points after that the triangulated mesh was realized with 5.000 .000 of triangles (Figure 9). As final output the DSM and orthophoto mosaic have been realized as well (Figure 10). The processing phase was very time spending: a Pentium i7 $3.60 \mathrm{GHz}$, GPU 2 Nvidia GTX 460 and 32 GB of RAM extract all the results in 4 days.

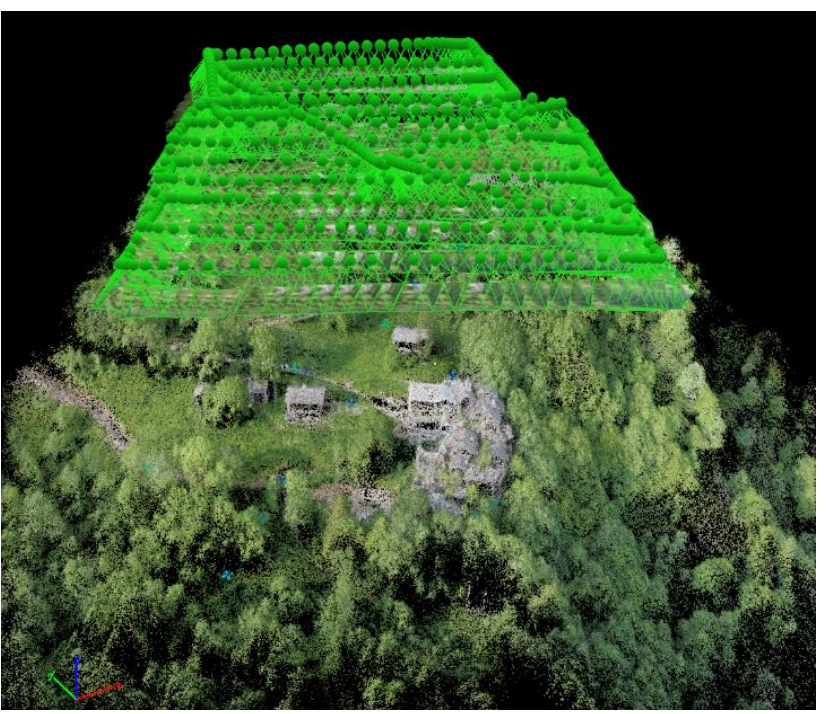

Figure 8A screen shot of the oriented images in the area of Campofei

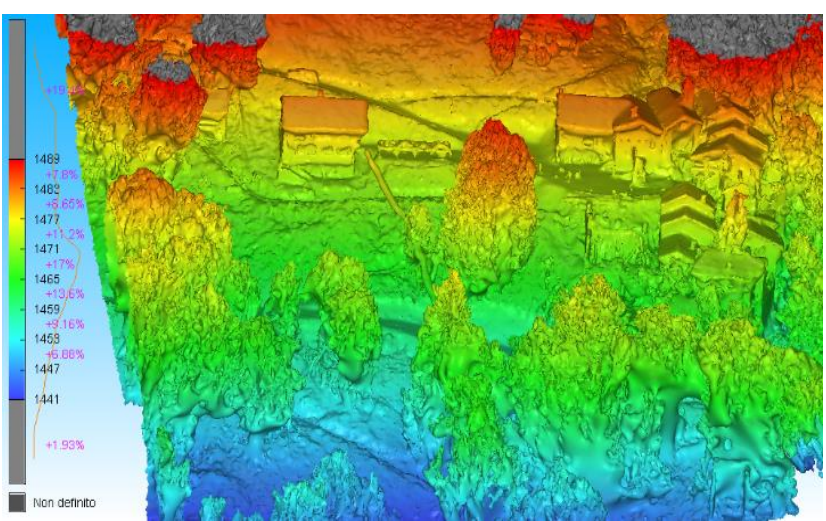



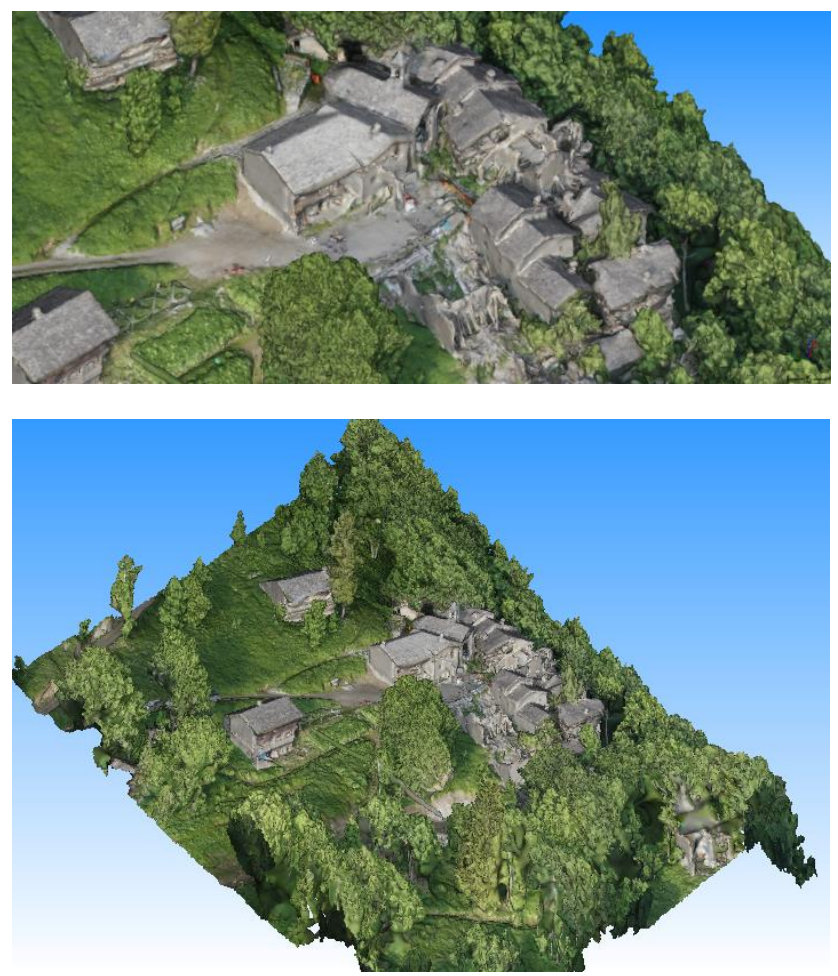

Figure 9. 3D textured model (altimetric model in false colors according to altimetry $(\mathrm{m})$ in the top; a zoom in the center of the village above; entire area below)
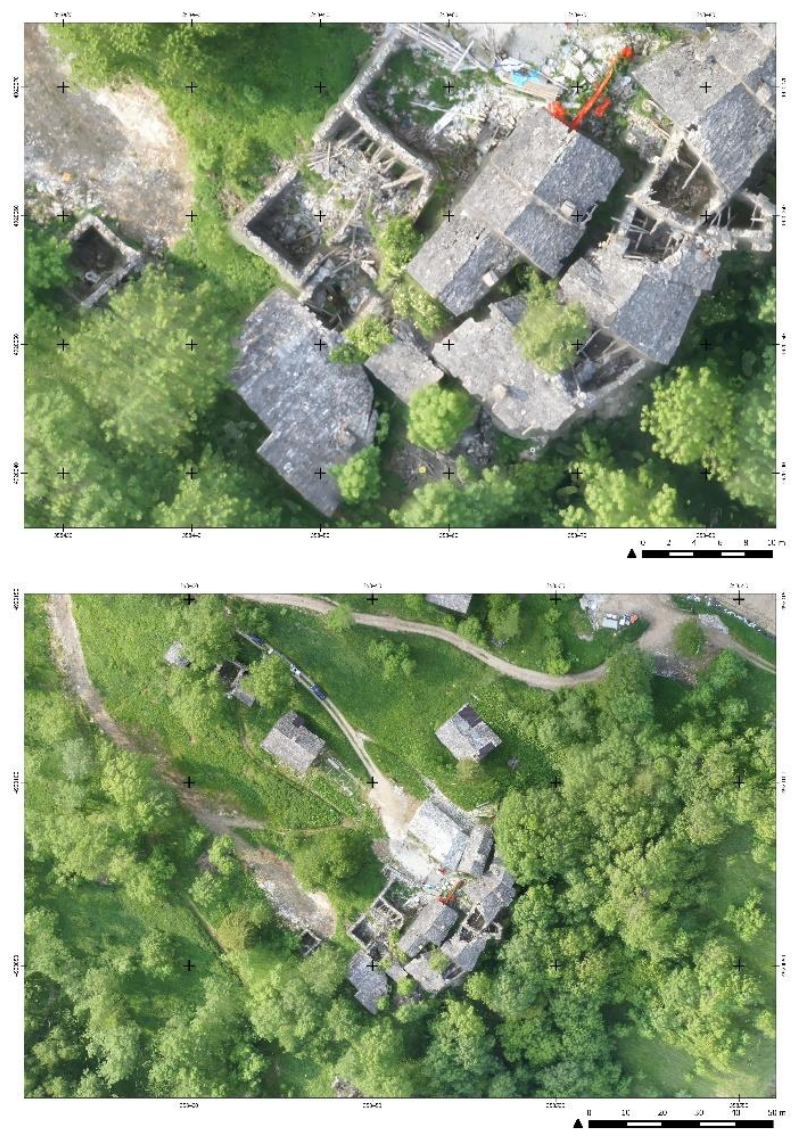

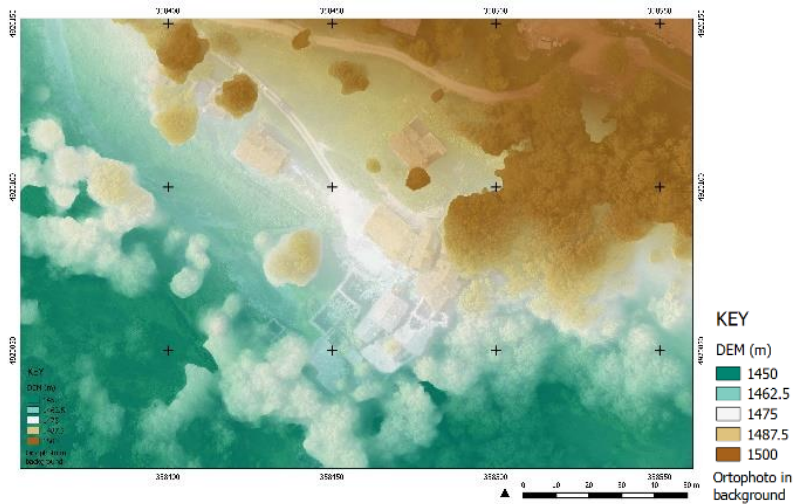

Figure10.Orthophoto (prev. column), a zoom in the center of the village above entire analyzed area center, and (here) DSM.

\subsection{Improving results by Data fusion}

According to the difficulties founded in the registration of the TLS data in the present work an experimental workflow for the registration of terrestrial clouds, with the support of control points derived by UAV survey, was carried out in three steps:

- $1^{\circ}$ STEP: Registration using Tie Points (TPs) and (few) topographic GCPs

- $2^{\circ}$ STEP: Registration using GCPs derived from UAV survey

- $3^{\circ}$ STEP: Registration using total station measurements and UAV survey GCPs

Despite the difficulties also observed for the measurement with GPS/GNNS technique of several GCPs used for the flight orientation (caused also by prosaic problems of a rich canopy cover), we can consider that the flight results were significantly better than those of terrestrial laser scanning survey were.

Downstream of this consideration, we therefore planned to repeat the scans registration of the $1^{\circ}$ STEP (Par. 3.2.1), based on shape recognition scans registration and then a target based georeferencing, by adding geometric constraints to the scans alignment in following steps.

3.4.1 $2^{\circ}$ STEP: Registration with TS GCP and UAV GCP. A first strategy to improve the first traditional scans registration has been performed using additional constraints such as the 3D coordinates of some ground points measured with GPS, with the aim to support the photogrammetric block orientation.

The advantage of these points, as can be noted from the distribution shown in the Figure 11, is that although they have not an optimum distribution for the flight cover, they are fairly well distributed for terrestrial cloud.

The new results of scans registration are very similar to the previous situation, only slightly improved.

For the two blocks, presented in Par. 3.2.1,it has been tried to align them again with automate algorithm of the software based on shape recognition in the 3D cloud space, but also helped by increasing TPs into scans. Then the entire block have been aligned together in the reference system by target-based registration algorithm with the help of coordinates. The results are shown in Figure 12. The mean error in topographic GCPs is around $20 \mathrm{~mm}$. The consideration made at this point was that a small number of points that cooperate to increase the recording constraints have resulted in a slight improvement. 


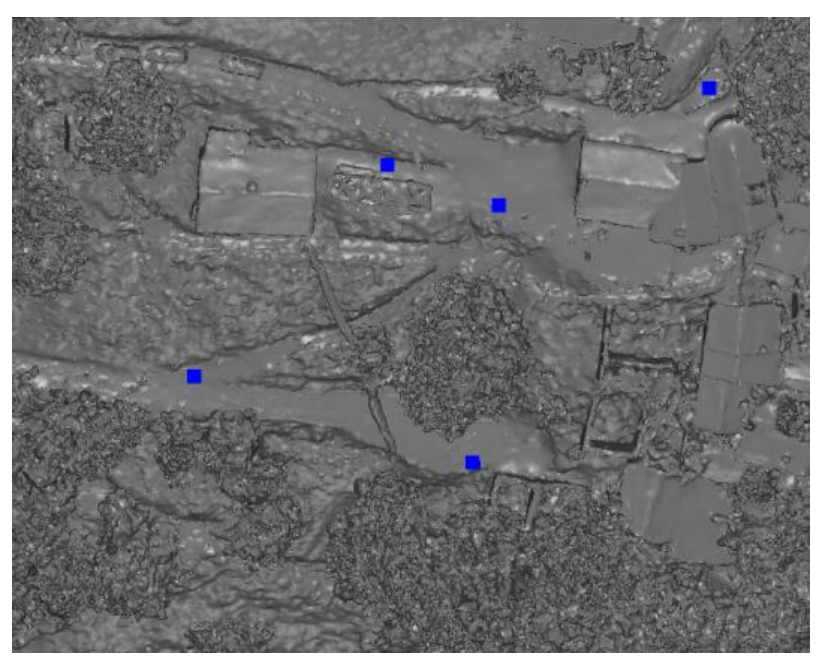

Figure 11. Position of GCP measured by GPS techniques used as further constrain in terrestrial scans registration

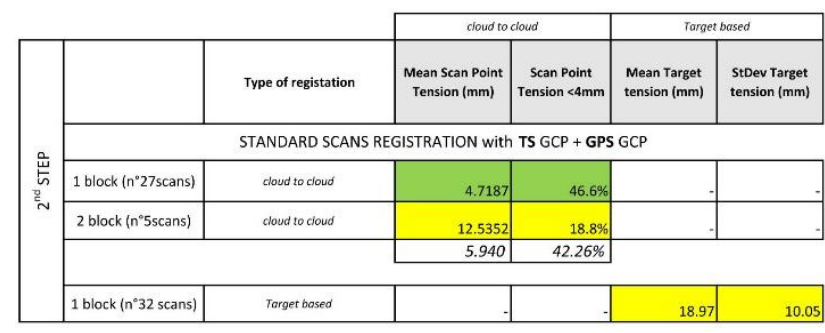

Figure 12. Accuracy results after additional constrains in clouds registration: $2^{\circ}$ STEP

3.4.2 $3^{\circ}$ STEP: Registration with TS GCP, UAV GCP and natural GCP from UAV model. It was therefore decided to increase the number of points by choosing not only points on the ground but also on buildings and their roofs (Figure 13), logically extracted from UAV DSM/3D model, in order to increase significantly the geometric constraints to registration. At this new step the results became extremely accurate; this new integration allow to the employed software to obtain a solution that fit the requirement accuracy for architectural purpose (Figure 14). As expected, these results are connected to the employed point for the registration used as GCPs, is not possible to insert some Check Points in Scene and therefore in order to accurately understand the achieved accuracy on external points another software is needed.

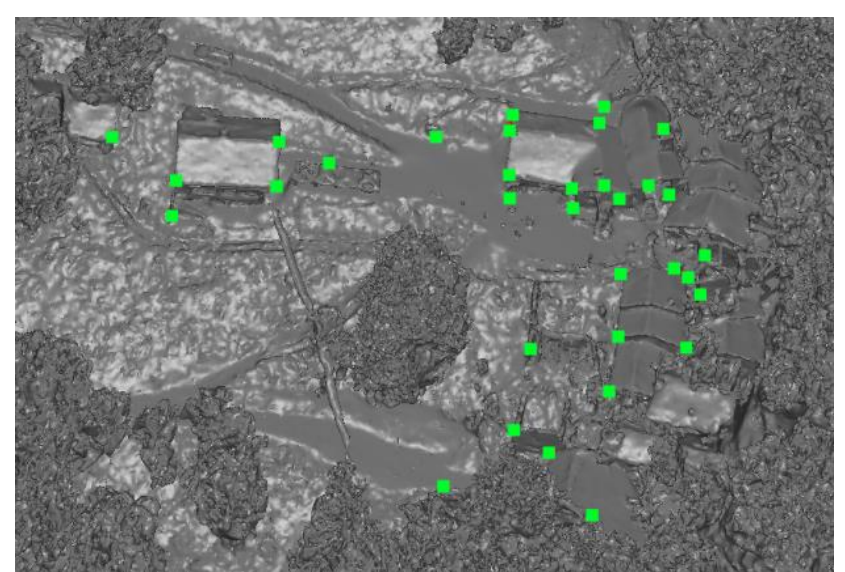

Figure 13. Position of GCP measured on the achieved UAV model as further constrain in terrestrial scans registration

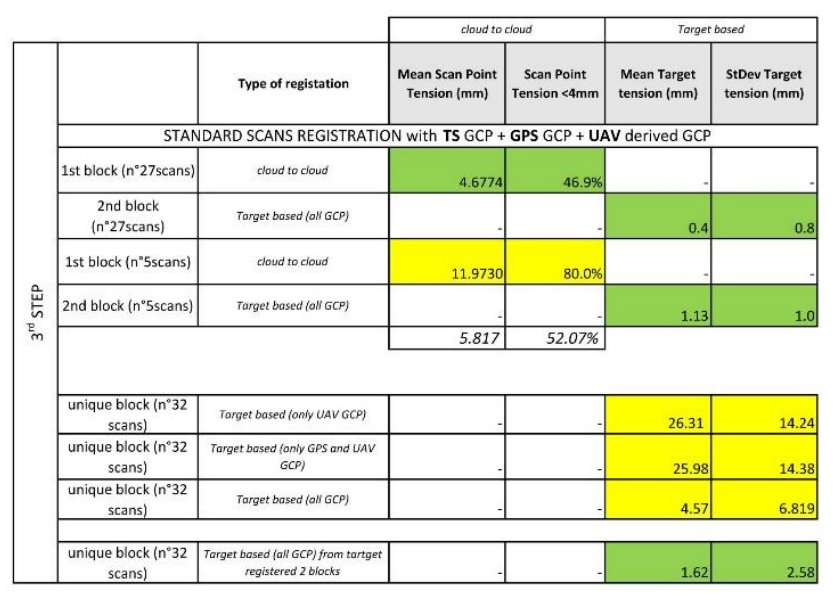

Figure 14. Accuracy results after additional constrains in clouds registration: $3^{\circ}$ STEP

\section{RESULTS AND FINAL ASSESSMENT}

The last step of the test was therefore the quality evaluation of the scans alignment in three steps with the increase of stiff constrains measurement of the discrepancy between the achieved registration results and some Check Points. In the following Figure 16 are reported the obtained results on 5CPs well distributed on the analysed area (Figure 15).

The coordinates acquired via topographic technique of some target measured on the terrain but not used in the registration process, have been compared with the correspondent target position in the registered clouds blocks. Appreciable results in Table 5 clarify that the registration, here in the $3^{\circ}$ step case, can be considerably evaluate as good, despite the difficult in that context, to acquire and manage spatial data.
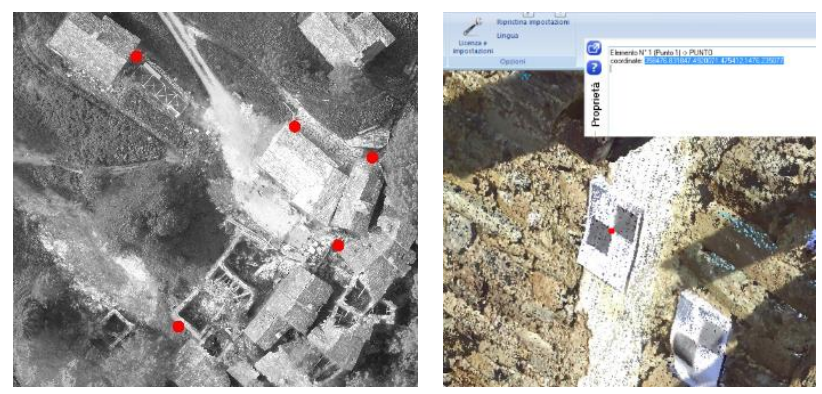

Figure 15. Marked CPs and measured coordinates on the target in registered cloud for a following comparison with TS measured coordinates (Table 5).

\begin{tabular}{|c|c|c|c|c|c|c|c|}
\hline & & M315 & DM409 & DM416 & D111 & $D 116$ & \\
\hline \multirow{3}{*}{ 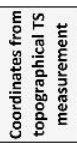 } & $\mathrm{x}$ & \multirow{2}{*}{$\begin{array}{r}358476.832 \\
4920071.476\end{array}$} & 358479.962 & 358467.081 & 358433.861 & \multicolumn{2}{|l|}{358417.556} \\
\hline & $Y$ & & 4920088.253 & 4920093.114 & 4920108.988 & 4920122.520 & \\
\hline & z & 1476.236 & 1481.322 & 1481.662 & 1477.409 & 1477.770 & \\
\hline \multirow{3}{*}{ 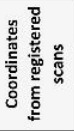 } & $x$ & \multirow{2}{*}{$\begin{array}{c}358476.832 \\
4920071.475\end{array}$} & 358479.987 & 358467.095 & 358433.838 & 358417.570 & \\
\hline & Y & & 4920088.268 & 4920093.093 & 4920108.961 & 4920122.524 & \\
\hline & z & 1476.235 & 1481.088 & 1481.425 & 1477.392 & 1477.748 & \\
\hline \multirow{4}{*}{ 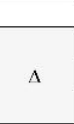 } & & & & & & & RMS (m) \\
\hline & $x$ & 0.0002 & -0.0250 & -0.0140 & 0.0229 & \multirow{3}{*}{\begin{tabular}{r|}
-0.0144 \\
-0.0043 \\
0.0223 \\
\end{tabular}} & 0.0185 \\
\hline & $Y$ & 0.0006 & -0.0146 & 0.0213 & 0.0273 & & 0.0177 \\
\hline & z & 0.0009 & 0.2340 & 0.2372 & 0.0168 & & 0.1220 \\
\hline
\end{tabular}

Figure 16. Discrepancy between the employed CPs and the point cloud coordinates. 
These results have been assumed as relevant and challenging, because prove, for the whole workflow, the possibility of technique effective combination in the previous phase of drafting process and not only for final outputs. The real specificity and vulnerability of Landscape and Heritage Assets and in particular the challenge in documentation and mapping purposes of critical areas, as the one of Castelmagno, make interesting the test. In scarcely accessible areas, of course, the exploitation of alternative and helpful solutions have nowadays more and more to be tested and refine and standard workflow have to be improved for specific contexts.

The collaboration of sensors not only addressed of a final fusion of data, but rather a prior collaboration of metric information owned by GPS UAV acquisition can assist terrestrial LiDAR acquisition and adjust a traditional target scans registration. In a distinctive environment like this one, topographic measurement may be arduous to be collected, even if in this case have been indeed experimentally executed to prove and test this purpose.

\section{ACKNOWLEDGEMENTS}

The authors are grateful to people involved for several years in valorization projects of Alpine Landscape promoted by private foundation and local institutions of Castelmagno valley. They want to mention and sincerely thanks Prof. Daniele Regis and municipalities Committee of Castelmagno villages. They would like to especially thank all students and tutors attending the DIRECT Team participating in the experience.

\section{REFERENCES}

Ahmadabadian, A. H., Robson, S., Boehm, J., Shortis, M., Wenzel, K., Fritsch, D., 2013. A comparison of dense matching algorithms for scaled surface reconstruction using stereo camera rigs. ISPRS Journal of Photogrammetry and Remote Sensing, 78, pp. 157-167.

Bae, K. H., Lichti, D. D., 2006. Automated registration of unorganised point clouds from terrestrial laser scanners. Curtin University of Technology.

Ballarin, M., Buttolo, V., Guerra, F., Vernier, P., 2013. Integrated surveying techniques for sensitive areas: San Felice sul Panaro.I n: ISPRS Annals of the Photogrammetry, Remote Sensing and Spatial Information Sciences, 5, W1.

Barsanti, S., Remondino, F., Fenández-Palacios, B., Visintini, D., 2014. Critical factors and guidelines for 3D surveying and modelling in Cultural Heritage. International Journal of Heritage in the Digital Era, 3(1), pp. 141-158.

Bastonero, P., Donadio, E., Chiabrando, F., Spanò A., 2014: Fusion of 3D models derived from TLS and image-based techniques for $\mathrm{CH}$ enhanced documentation. In: Isprs annals of the photogrammetry, remote sensing And Spatial Information Sciences, Riva del Garda, 23 - 25 June 2014:pp. 73-80.

Blais, F., Beraldin, J.-A., 2006. Recent Developments in 3D Multi-modal Laser Imaging Applied to Cultural Heritage. In: Machine Vision and Applications, pp. 395-409.

Botequilha-Leitão, A., Ahern, J., 2002. Applying landscape concepts and metrics in sustainable landscape planning. Landscape and Urban Planning, 59
Chiabrando, F. Spanò, A., 2013. Points clouds generation using TLS and dense-matching techniques. A test on approachable accuracies of different tools. In: Isprs Annals Of The Photogrammetry, Remote Sensing And Spatial Information Sciences, II-5/W1. Pp. 67-72.

Chiabrando, F., Lingua, A., Piras., M., 2013. Direct photogrammetry using UAV: tests and first results..In: :the International Archives of the Photogrammetry, Remote Sensing and Spatial Information Sciences, $1 \mathrm{~W} 2$.

Coscia C, Regis D., Spanò A., ALPINE CLE Complex Landscape Environment. CamPofei e le borgate di Castelmagno in Alta Valle Grana come sistema complesso. Mobilità sostenibile, turismo, produzione e cultura, FeasibilityStudy, in press.

Del Pizzo, S.; Troisi, S., 2011. Automatic Orientation of Image Sequences in Cultural Heritage. In: Proceedings of the 4th ISPRS International Workshop 3D-ARCH 2011 Trento, Italy, 2-4 March 2011; Volume 38, Part 5/W16. 99.

Fritsch, D., Khosravani, A.M., Cefalu, A., Wenzel, K., 2011: Multi-Sensors and Multiray Reconstruction for Digital Preservation. - Photogrammetric Week 2011, Berlin, Germany, pp. 305-323.

Fritsch, D., Abdel-Wahab, M., Cefalu, A., Wenzel, K., 2012. Photogrammetric Point Cloud Collection with Multi-camera System. In: Progress in Cultural Heritage Preservation: 4th International Conference, pp. 11-20.

Gerke, M., Nex, F., Jende, P., 2016. Co-registration of terrestrial and UAV-based images - experimental results. In: the International Archives of the Photogrammetry, Remote Sensing and Spatial Information Sciences XL-3/W4, pp. 11-18.

Grenzdörffer, G. J., Engel, A., Teichert, B., 2008. The photogrammetric potential of low-cost UAVs in forestry and agriculture. In: International Archives of the Photogrammetry, Remote Sensing and Spatial Information Sciences. Vol. XXXVII. Part B1.

Gruen, A., 2009. Image-based 3D recording and modeling of landscapes and large cultural heritage sites. In: ARCHAIA Case Studies on Research Planning, Characterization, Conservation and Management of Archaeological Sites

Guarnieri, A., Remondino, F., Vettore, A., 2006. Digital photogrammetry and TLS data fusion applied to Cultural Heritage 3D modeling. In: the International Archives of the Photogrammetry, Remote Sensing and Spatial Information Sciences, 36(part 5).

Gressin, A., Mallet, C., Demantké, J., David, N., 2013. Towards 3D lidar point cloud registration improvement using optimal neighborhood knowledge.ISPRS Journal of Photogrammetry and Remote Sensing, 79, 240-251.

Guidi, G., Remondino, F., Russo, M., Menna, F., Rizzi, A., Ercoli, S., 2009. A multi-resolution methodology for the 3D modelling of large and complex archaeological areas. International Journal of Architectural Computing, Vol. 7(1), pp. 39-55. 
Hullo, J.F., Grussenmeyer P., Fares S., 2009. Photogrammetry and dense matching approach applied to the documentation of the cultural heritage site of Kilma (Saudi Arabia). In: CIPA 2209 XXII International Symposium, Kyoto, Japan, pp. 1-6.

Irschara, A., Kaufmann, V., Klopschitz, M., Bischof, H., Leberl, F., 2010. Towards fully automatic photogrammetric reconstruction using digital images taken from UAVs. In: Proceedings International Society for Photogrammetry and Remote Sensing Symposium, 100 Years ISPRS. Advancing Remote Sensing Science, pp. 65-70.

Kersten, T.P., Lindstaedt, M., 2012a. Potential of Automatic 3D object reconstruction from multiple Images for applications in Architecture, Cultural Heritage and Archaeology. International Journal of Heritage in the Digital Era, Multi Science Publishing, pp. 399-420.

Kersten, T.P., Lindstaedt, M., 2012b. Image-Based Low-Cost Systems for Automatic 3D Recording and Modelling of Archaeological Finds and Objects. Proc. EuroMed 2012 Conference, M. Ioannides et al. (Eds.), LNCS 7616, Springer Berlin Heidelberg, pp.1-10.

Kersten, T.; Mechelke, K.; Lindstaedt, M.; Sternberg, H., 2009. Methods for geometric accuracy investigations of terrestrial laser scanning systems. Photogrammetrie-Fernerkundung Geoinformation 2009, pp. 301-315.

Korzeniowska, K., Łackam, M., 2011. Generating DEM from Lidar data - comparison of available software tools. In: :the International Archives of the Photogrammetry, Remote Sensing and Spatial Information Sciences, Vol. 22, pp. 271-284

Koutsoudis, A., Vidmar, B., Ioannakis, G., Arnaoutoglou F., Pavlidis, G., Chamzas, C., 2013. Multi-image 3D reconstruction data evaluation. Journal of Cultural Heritage, Vol. 15, Issue 1, pp. 73-79.

Maiellaro, N., Zonno, M., and Lavalle, P., 2015. Laser scanner and camera-equipped UAV architectural surveys. In: :the International Archives of the Photogrammetry, Remote Sensing and Spatial Information Sciences., XL-5/W4, pp. 381-386.

Martin-Beaumont, N., Nony, N., Deshayes, B., PierrotDeseilligny, M., De Luca, L., 2013. Photographer-friendly work-flows for image-based modelling of heritage artefacts. ISPRS, XXIV International CIPA Symposium, Strasbourg, France, Vol. XL, Part. 5/W2, pp. 421-424.

Moussa, W., Abdel-Wahab, M., Fritsch, D., 2012: An Automatic Procedure for Combining Digital Images and Laser Scanner Data. In: : the International Archives of the Photogrammetry, Remote Sensing and Spatial Information Sciences; Melbourne, Australia, Vol. XXXIX, Part B5, pp. 229-234.

Nex, F.,Remondino, F., 2014. UAV for 3D mapping applications: a review.Applied Geomatics, 6(1), 1-15.

Nony, N., De Luca, L., Godet, A., Pierrot-Deseilligny, M., Remondino, F., Van Dongen, A., Vincitore, M., 2012. Protocols and Assisted Tools for Effective Image-Based Modeling of Architectural Elements. Proc. EuroMed 2012 Conference, M. Ioannides et al. (Eds.), LNCS 7616, Springer Berlin Heidelberg, pp. 432-439.
Patias, P., Santana, M., 2012. Introduction to heritage documentation. CIPA heritage documentation best practices and applications, Series 1, 2007-2009, pp. 9-13.

Phillips, S., Krystek, M., Shakarji, C., Summerhays, K., 2009. Dimensional measurement traceability of 3D imaging data. Proc. SPIE 7239, Three-Dimensional Imaging Metrology, $72390 \mathrm{E}$

Ramos, M. M., Remondino, F., 2015. Data fusion in Cultural Heritage-A Review.In: :the International Archives of the Photogrammetry, Remote Sensing and Spatial Information Sciences, 40(5), 359.

Remondino, F., Spera, M.G., Nocerino, E., Menna, F., Nex, F., 2014: State of the art in high density image matching. The Photogrammetric Record, Vol. 29(146), pp. 144-166, DOI: 10.1111/phor.12063

Robertson D.P. Cipolla R.., 2009. Structure from Motion.InVarga, M., editors. Practical Image Processing and Computer Vision, John Wiley, 2009.

Sammartano, G., Spanò, A. 2016. DEM generation based on UAV photogrammetry data in critical areas. Proceedings of the 2ndGISTAM International Conference onGeographical Information Systems Theory,Applications and Management, Rome, April 26 - 27, 2016

Sauerbier, M., Eisenbeiss, H., 2010: UAVs for the documentation of archaeological excavations. IAPRS\&SIS, Vol. 38(5), Newcastle upon Tyne, UK

Taccola, E., Parra, M. C., Ampolo, C., 2014. The sanctuary of Punta Stilo at Kaulonia-Monasterace (Rc, Italy): preliminary results of the close range photogrammetric surveys 20122013.In: the International Archives of Photogrammetry, Remote Sensing and Spatial Information Sciences, 40(5), 559..

Triggs, B., McLauchlan, P., Hartley, R., Fitzgibbon, A., 2000. Bundle adjustment - a modern synthesis. In: Vision Algorithms: Theory and Practice, Lecture Notes in Computer Science 1883, Springer-Verlag, Berlin, Germany, pp. 298-.372.

Vosselman, G., 2002. Fusion of Laser Scanning Data, Maps, and Aerial Photographs for Building Reconstruction.In: IEEE transactions on geosciences and remote sensing, Vol. 1, pp. 8588.

Xu, Z.; Wu, L.; Shen, Y.; Li, F.; Wang, Q.; Wang, R., 2014. Tridimensional Reconstruction Applied to Cultural Heritage with the Use of Camera-Equipped UAV and Terrestrial Laser Scanner. Remote Sensing2014, 6, pp. 10413-10434

Wenzel, K., Abdel-Wahab, M., Cefalu, A., Fritsch D., 2012: High-Resolution Surface Reconstruction from Imagery for Close Range Culture Heritage Applications. In: the International Archives of the Photogrammetry, Remote Sensing and Spatial Information Sciences, Melbourne, Australia, Vol. XXXIX, Part B5, pp.133-138.

Roncella, R.; Re, C.; Forlani, G., 2011. Performance Evaluation of a Structure and Motion Strategy in Architecture and Cultural Heritage. In: Proceedings of the 4th ISPRS International Workshop 3DARCH 2011:, Trento, Italy, 2-4 March 2011; Volume 38, Part 5/W16. 